\section{BIOLOGICAL MONITORING OF BENZENE AFTER EXPOSURE TO FRESH CRUDE OIL SPILLED AT SEA IN AN OIL SPILL FIELD TRIAL}

${ }^{1}$ I Gjesteland*, 1,2BE Hollund, ${ }^{1,2}$ J Kirkeleit, ${ }^{3} \mathrm{P}$ Daling, ${ }^{1} \mathrm{M}$ Bråtveit. ${ }^{1}$ Department of Global Public Health and Primary Care, Occupational and Environmental Medicine, University of Bergen, Bergen, Norway; ${ }^{2}$ Department of Occupational Medicine, Haukeland University Hospital, Bergen, Norway; ${ }^{3}$ Department of Environmental Technology, SINTEF Ocean, Trondheim, Norway

\subsection{6/oemed-2018-ICOHabstracts.1046}

Introduction Oil spill cleanup personnel could be exposed to benzene during cleanup of accidental spill of crude oil at sea. S-Phenyl Mercapturic Acid (SPMA) is reported to be a sensitive urinary marker of exposure to low levels of benzene, but there is a lack of information on biological uptake of benzene during cleanup of oil spills. The aim of this study was to investigate the exposure to benzene during an oil spill by measuring the concentration of SPMA in urine for subjects participating in an oil spill field trial at sea.

Methods The study included 22 subjects taking part in an oil spill field trial in the North Sea with two types of fresh crude oil. The subjects were located in open air sampling boats close to the oil slick $(<50 \mathrm{~m})$, on the main deck of two large vessels further from the oil slick $(100-200 \mathrm{~m})$, or indoors on the vessel bridge. Urine samples were collected before and after work shift and analysed for S-Phenyl Mercapturic Acid, 1Hydroxypyrene and cotinine, which are urinary markers of benzene, PAH and tobacco exposure, respectively.

Results SPMA was not detected in the urine samples of subjects wearing protective masks and in the control group. Among the six subjects who reported not to wear protective masks during the spill the concentration of SPMA in urine ranged $0.5-3.3 \mu \mathrm{mol} / \mathrm{mol}$. They were all located in the boat closest to the oil spill.

Discussion We have previously reported that mean personal exposure to benzene in air was $0.43 \mathrm{ppm}$ for the personnel in the boat closest to the oil spill. The present study suggests that work with fresh oil spilled at sea might cause biological uptake of benzene. Appropriate personal respiratory protection should be used to prevent such uptake.

\section{Occupational Medicine}

\section{THE DEVELOPMENT OF AN ALCOHOL SCREENING GUIDELINE FOR OCCUPATIONAL PHYSICIANS}

\footnotetext{
1,2Marie-Claire Lambrechts*, 1,3 Lode Godderis. ' $\mathrm{KU}$ Leuven, University of Leuven, Centre Environment and Health, Belgium; ${ }^{2}$ VAD Flemish centre of expertise on alcohol and other drugs, Brussels, Belgium; ${ }^{3}$ Idewe, External Service for Prevention and Protection at Work, Heverlee, Belgium
}

\subsection{6/oemed-2018-ICOHabstracts. 1047}

Introduction Screening tools provide occupational physicians the ability to inform employees about their alcohol consumption, and the possibility to take preventive measures. In addition, the occupational physician can detect risky and harmful alcohol use. So far, clear screening guidelines to deal with alcohol misuse in occupational health setting are lacking.

Methods Between June 2016 and March 2017, we organised four World Cafés with a motivated group of occupational physicians. The World Café method is a Large Scale
Intervention and an evidence-based approach in which stakeholders actively participate. The different screening tools were discussed and the guideline was concretized.

Result The Alcohol Use Disorders Identification Test-Consumption (AUDIT-C) was selected as the most adequate and feasible instrument to screen workers. This shortened version of the AUDIT (the first 3 of 10 questions focuses on the consumption of alcohol) is a brief, validated screening instrument for risky drinking and alcohol misuse. The working group advised to organise targeted screening during individual medical examinations (i.e. pre-recruitment medical examination, periodic medical examination, occupational aptitude test, return to work screening and consultations with workers showing deteriorated job performances). We made flowcharts for each type of examination, with an overview of the possible initiatives of occupational physicians based on the score of the screening test, i.e. brief interventions. The guideline also stipulated in which circumstances additional biomarkers are required. Finally, the use of AUDIT-C for health promotion initiatives was concretized. In that case, results will be analysed on a company level and may thus form the basis for prevention measures.

Conclusion This consensus guideline is the first guideline for occupational physicians. It will now be submitted for validation, subsequently followed by its implementation.

\section{SPECIFIC CAUSATION IN OCCUPATIONAL MEDICINE: PROPOSED MODIFICATIONS TO THE DECISION-MAKING PROCESS WITH PRACTICAL APPLICATIONS AND EXAMPLES}

'George Friedman-Jiménez, ${ }^{2}$ Steven Markowitz. ${ }^{1}$ Bellevue/NYU Occupational and Environmental Medicine Clinic, NYU School of Medicine, New York, NY, USA; ${ }^{2}$ Queens College, City University of NY, Barry Commoner Centre for Health and the Environment, Queens, NY, USA

\subsection{6/oemed-2018-ICOHabstracts.1048}

Introduction The process of determining occupational aetiology of a disease in an individual patient (etiologic diagnosis or Specific Causation) is central to the current practice of occupational medicine. We typically need to determine Specific Causation to assist us in decision-making related to safe return-to-work, prevention of worsening of disease or re-injury of a patient, as well as wage replacement and reimbursement of medical care expenses for patients with disabling diseases potentially of occupational aetiology. Incorrectly attributing or denying occupational causes of disease can each cause serious harm to patients, their families, their employers, coworkers, and society. Potential contributors to inaccurate determination of Specific Causation include diagnostic, toxicologic, mechanistic and exposure-related uncertainties as well as scientific limitations of medicolegal concepts, including the 'probability of causation' and 'more likely than not' criteria sometimes used in workers' compensation decision-making. Improving accuracy of determination of Specific Causation is deserving of additional research attention.

Methods We review the current status of causal inference at the individual level in occupational medicine and apply some of the recently developed concepts in causal inference theory from epidemiology and statistics to the decision-making process in clinical occupational medicine.

Results We illustrate with examples of patients with cancer, respiratory disorders or chemical toxicity some of the 